\title{
Bacterial Ecology of Peritonitis in a Sub-Saharan Peritoneal Dialysis \\ Unit
}

\author{
Keywords: Peritoneal dialysis; Peritonitis, Bacterial ecology; Dakar \\ Abstract \\ Introduction: Peritonitis is a common and serious complication of \\ Peritoneal Dialysis (PD). Peritonitis is a major cause of PD technique \\ failure and conversion to long-term hemodialysis. After acquiring 10 \\ years of experience with this complication, we conducted this study \\ to determine the bacterial ecology profile of peritoneal infections in \\ Dakar.
}

Patients and methods: A retrospective descriptive and analytical study in PD unit of the Nephrology Department at Aristide Le Dantec University Hospital was performed during the period of 1 January 2011 to 31 December 2013. We included all patients on PD who had a peritoneal infection.

Results: Seventy two (72) episodes of peritonitis were diagnosed in 51 patients with a peritonitis rate of 1 episode/21.03 patientmonths. The sex ratio was 0.6 . Nephroangiosclerosis (56.87\%), chronic glomerulonephritis (25.49\%), and diabetic nephropathy (3.92\%) were the most common causes of end stage renal disease. Among the patients who had infectious peritonitis, 50 (98.03\%) were on continuous ambulatory peritoneal dialysis. Peritonitis was more common during the wet season (41 cases $(56.94 \%)$ ) than during the dry season (31 cases $(43.06 \%)$ ). The drained fluid was cloudy in $76.4 \%$, purulent in $2.77 \%$ and clear in $20.83 \%$ of cases. The culture was negative in 21 cases and positive in 51 cases. The pathogens found were Gram-positive organisms in $60.78 \%$ and Gram negative in $39.22 \%$ of cases. Staphylococcus aureus was present in 25 patients $(45.12 \%)$ and Pseudomonas aeruginosain 8 patients (17.64\%). Antimicrobial susceptibility testing did not detect any multidrug resistance or vancomycin-resistant strains. Therapeutically, ciprofloxacin per OS was used as a first-line therapy in all patients (100\%) and intraperitoneal ceftriaxone in 61 episodes (84.72\%). The average duration of treatment was $17 \pm 3$ days. The treatment was favorable in 48 cases.

Conclusion: Peritoneal infections remain common in our patients, mainly with Gram-positive bacilli. Prevention and better care of peritoneal infections are necessary to ensure an effective PD technique.

\section{Introduction}

Peritonitis is a common and serious complication of Peritoneal Dialysis (PD). Peritonitis is the direct or major contributing cause of death in around $16 \%$ of PD patients $[1,2]$. In addition, severe or prolonged peritonitis leads to structural and functional alterations of the peritoneal membrane, eventually leading to membrane failure. Peritonitis is a major cause of PD technique failure and conversion to long-term hemodialysis. The most commonly encountered bacteria are staphylococcus and Gram-negative bacilli [3]. Difficulties in the treatment of bacterial infections with $\mathrm{PD}$ are related to the frequency of multidrug resistance of the causal agent. Identification of the organism and subsequent antibiotic sensitivities help in guiding the choice of antibiotic, and the type of organism often indicates the possible source of infection. After 10 years of experience with this complication, this study was conducted to shed light on the bacterial ecology profile of peritoneal infections in Dakar.

\section{Journal of \\ Urology \& Nephrology}

\author{
Lemrabott $\mathrm{AT}^{1^{*}}$, Faye $\mathbf{M}^{1}$, Faye $\mathbf{M o}^{1}$, Kane $\mathrm{Y}^{2}$, Cissé \\ MM $^{1}$, Baldé MS ${ }^{1}$, Fall K ${ }^{1}$, Seck SM ${ }^{3}$, Keita ARI ${ }^{1}, \mathrm{Ka}$ \\ $E^{1}$, Niang $A^{1}$ and Diouf $B^{1}$
}

${ }^{\prime}$ Nephrology Department, Aristide Le Dantec University Hospital, Dakar, Senegal

${ }^{2}$ Internal Medicine and Nephrology, Assane Seck University, Ziguinchor, Senegal

${ }^{3}$ Internal Medicine and Nephrology, Gaston Berger University, Saint-Louis, Senegal

Address for Correspondence

Ahmed Tall LEMRABOTT, Nephrology Department, Aristide Le Dantec University 30, avenue Pasteur, BP: 3001, Dakar, Senegal, Tel: 00221338216773, E-mail: ahmedtall35@hotmail.com

Submission: 04 December, 2018

Accepted: 26 December, 2018

Published: 28 December, 2018

Copyright: $\odot 2018$ Lemrabott AT, et al. This is an open access article distributed under the Creative Commons Attribution License, which permits unrestricted use, distribution, and reproduction in any medium, provided the original work is properly cited.

\section{Patients and Methods}

A retrospective, descriptive, and analytical study was conducted from 1 January 2011 to 31 December 2013 in the peritoneal dialysis unit of Nephrology Department of Aristide Le Dantec Hospital. It is the only referral center for peritoneal dialysis in the country. All patients treated with PD who had a peritoneal infection were included. Data analysis was performed using data collection sheets from records and hospital registers.

The socioeconomic status was evaluated based on patients' monthly income. It was defined as low when the monthly income was less than 68.7 euros, as medium when between 68.7 euros and 229 euros, high if it exceeded 229 euros.

Peritonitis was diagnosed when at least 2 of the following were present: clinical features consistent with peritonitis (abdominal pain and/or cloudy dialysis effluent), dialysis effluent white cell count $>100$ cells $/ \mu \mathrm{L}$ with $>50 \%$ neutrophils, and positive dialysis effluent culture.

For bacteriological tests, we performed a Bedside inoculation of 5 - $10 \mathrm{~mL}$ effluent in 2 (aerobic and anaerobic) blood-culture bottles. Gram stain was performed in all patients included, the culture was treated using a BACTEC 9120 and the associated software (Becton Dickinson Microbiology Systems, Sparks, Md).

After bacterial identification, different antibiotics were tested with reference to recommendations of the French Society of Microbiology [4] in order to determine antibiotic susceptibility.

The patient was considered cured when the cytology of peritoneal fluid returned to standard levels (white blood cell count $<100$ cells/ $\mathrm{ml}$ ) along with resolution of clinical signs of peritonitis.

Surgical implantation of a double cuff Tenckhoff catheter was performed using local anesthesia. For continuous ambulatory peritoneal dialysis (CAPD), a Y-set connection system for exchanges 
Citation: Lemrabott AT, Faye M, Faye M, Kane Y, Cissé MM, et al. Bacterial Ecology of Peritonitis in a Sub-Saharan Peritoneal Dialysis Unit. J Urol Nephrol. 2018;5(1): 3

ISSN: 2380-0585

was used; Baxter Healthcare (Baxter Healthcare Corporation, Deerfield, IL, USA) systems were used.

The Baxter Home Choice Cycler was used for Automated Peritoneal Dialysis (APD). Standard lactate-based solutions containing $1.36 \%, 2.27 \%$ and $3.86 \%$ dextrose were used. Icodextrin and amino acid-based solutions were used in selected cases.

The collected data were entered and analyzed using Epi Info 3.5.1 software. Our results were divided into global and analytical categories. Quantitative variables were expressed as mean and standard deviation, whereas qualitative variables were given as numbers and percentages. The study was conducted with crosstabs to compare frequencies. Chi-square test or Fisher's test was applied, and the difference was considered statistically significant if $p$ value was $<0.05$.

\section{Results}

Over 1514 months, 72 episodes of peritonitis were diagnosed in 51 patients with a peritonitisrate of 1 episode/21.03 patient-months (0.57 episodes/year). There were 19 women and 32 men with a sex ratio of 0.6 . Socioeconomic status was low in $62.51 \%$, medium in $15.27 \%$ and high in $22.22 \%$ of cases. Nephroangiosclerosis (56.87\%), chronic glomerulonephritis (25.49\%) and diabetic nephropathy (3.92\%) were the most common causes of ESRD. Among the patients who had infectious peritonitis, 50 (98.03\%) were treated by Continuous Ambulatory Peritoneal Dialysis (CAPD). The mean duration of patient education was $12 \pm 5$ days. 41 (57\%) episodes of peritonitis were noted during the wet season while 31 (43\%) episodes occurred during the dry season. The main clinical signs seen are shown in (Table 1). the mean delay between onset of symptoms and sending culture was 36 hours (range 3-48h). Infection of the exit site was the starting point in $59.7 \%$ of cases. The other entry points are shown in (Table 2). The drained fluid was cloudy in $76.4 \%$, purulent in $2.77 \%$, and clear in $20.83 \%$ of cases. The mean white cell count was $2612.57 \pm 65 / \mathrm{ml}$. The culture was negative in 21 cases and positive in 51 cases. Out of the 51 episodes with positive cultures, $60.78 \%$ were Gram-positive organisms, while $39.22 \%$ were Gram negative. For the 21 episodes with negative cultures, $46.88 \%$ were Gram-positive organisms, while $53.12 \%$ were Gram negative. Of the culture-negative patients, none were on antibiotics prior to bacteriological sampling. Other microorganisms that were found are shown in (Table 3). Staphylococcus aureus was present in 25 patients (45.12\%) while Pseudomonas aeruginosa was in 8 patients (17.64\%). Antimicrobial susceptibility tests revealed resistance to cefoxitin for 25 strains of Staphylococcus aureus. Two Meti-R strains (one case of resistance to cefoxitin, one case of resistance to Gentamicin) that were sensitive to other families were discovered. No resistance to vancomycin was found. All 25 strains were sensitive to glycopeptides, aminoglycosides and macrolides, except for one strain that was resistant to erythromycin. Among the streptococci isolated, one strain was resistant to Penicillin $G$ and other $\beta$-lactams. All enterococci were sensitive to oxacillin, to Penicillin $G$, and to $\beta$-lactam antibiotics with low resistance to aminoglycosides. Enterobacteria, a strain secreting $\beta$-lactamase at high levels, was sensitive to other antibiotics tested. One strain of Klebsiella pneumoniae was a high-level penicillinase producer, four
Table 1: Frequency of clinical signs.

\begin{tabular}{|c|c|c|}
\hline Functionala signs & Number & Percentage \\
\hline Stomach pains & 61 & $84.72 \%$ \\
\hline Vomiting & 58 & $80.55 \%$ \\
\hline Nausea & 58 & $80.55 \%$ \\
\hline Shivering & 22 & $30.55 \%$ \\
\hline Diarrhea & 13 & $18.05 \%$ \\
\hline
\end{tabular}

Table 2: Distribution according to entry points of germs.

\begin{tabular}{|c|c|c|}
\hline Causes of Peritonitis & Number & Percentage \\
\hline Exit-site infection & 43 & $59.72 \%$ \\
\hline Catheter-tunnel infections & 21 & $29.16 \%$ \\
\hline Acute gastroenteritis & $\mathbf{0 5}$ & $06.96 \%$ \\
\hline Undetermined causes & 03 & $04.16 \%$ \\
\hline
\end{tabular}

Table 3: Distribution according to the causative agent of peritonitis.

\begin{tabular}{|c|c|c|}
\hline Germs & Number & Percentage \\
\hline POSITIVE CELL CULTURE & 51 & $70.83 \%$ \\
\hline Staphylococcus aureus & 25 & $34.72 \%$ \\
\hline Streptococcus. Spp & 04 & $05.55 \%$ \\
\hline ENTEROBACTERIA & & \\
\hline - Escherichia coli & 02 & $02.77 \%$ \\
\hline - Seratiamarcesens & 01 & $01.38 \%$ \\
\hline - Citrobacter Spp & 03 & $04.16 \%$ \\
\hline- Enterobacter Spp & 01 & $01.38 \%$ \\
\hline - Klebsiella Oxyta & 05 & $07.00 \%$ \\
\hline - Klebsiella pneumonia & 02 & $02.77 \%$ \\
\hline NON-FERMENTING BACTERIA & & \\
\hline - Pseudomonas aeroginosa & 08 & $11.11 \%$ \\
\hline NEGATIVE CELL CULTURE & 21 & $29.16 \%$ \\
\hline
\end{tabular}

others produced penicillinase at lower levels, and another one had cross-resistance to fluoroquinolones. All Pseudomonas were sensitive to $\beta$-lactams, fluoroquinolones, and aminoglycosides.

Therapeutically, ciprofloxacin per os (PO) was used as a first-line therapy in all patients (100\%) and IntraPeritoneal(IP) ceftriaxone in 61 episodes (84.72\%) (Table 4). Median duration of treatment was 17 \pm 3 days. Twenty-eight (36\%) patients had been hospitalized with a mean duration of $8 \pm 3$ days. Evolution of peritonitis was favorable in 48 cases $(66.6 \%)$, unfavorable in 24 cases $(33.3 \%)$. The main reasons for removal of catheter were repetitive peritonitis with the same bacteria often in the context of poor adherence to therapy, and Pseudomonas aeruginosa peritonitis. Seventeen patients (23.61\%) were transferred to hemodialysis.

The peritonitis was statistically correlated with certain parameters such as: age (highest in subjects under 50 years of age, $p=0.001$ ), sex ( 45 cases in women $v s 27$ cases in men, $\mathrm{p}=0.001$ ), socioeconomic status (more common in patients with a low socioeconomic status, 
Citation: Lemrabott AT, Faye M, Faye M, Kane Y, Cissé MM, et al. Bacterial Ecology of Peritonitis in a Sub-Saharan Peritoneal Dialysis Unit. J Urol Nephrol. 2018;5(1): 3 .

ISSN: 2380-0585

Table 4: First-line indicated antibiotics.

\begin{tabular}{|c|c|c|}
\hline Drugs & Number & Percentage \\
\hline Ceftriaxone:1000 mg daily (IP) & 61 & $84.72 \%$ \\
\hline Ciprofloxacin: 250 mg twice daily(per os) & 72 & $100.00 \%$ \\
\hline Gentamycin: LD* 8 mg/L, MD*4 mg/L (IP) & 11 & $15.28 \%$ \\
\hline LD = Loading dose; MD = Maintenance Dose. & & \\
\hline
\end{tabular}

$p=0.001$ ), season (more frequent during the wet season, $p=0.003$ ), and site of infection (highest at peritonealsurgical site, $\mathrm{p}=0.002$ ).

\section{Discussion}

In our study, the rate of peritonitis was 1 episode/21.3 patientmonths or 0.5 episodes/year. Lioussfi reported a prevalence of 1 episode/21.07 patient-months [5]. The peritonitis rate found in our study was consistent with guidelines that recommend fewer than 0.5 episodes a year [6].

Infectious peritonitis was more frequent with CAPD than with APD (98.03\% vs. $1.96 \%)$ in our study. Enrique Villereal reported higher rates of peritonitis with CAPD $(94.20 \%)$ and less infectious peritonitis with APD (5.8\%) [7]. This can be explained by higher number of hand manipulations in CAPD.

Peritonitis occurred more often in wet season (56.94\%) than in dry season (43.06\%). This could be in line with sanitation problems that occur during the rainy season. Indeed, heavy rains cause flooding and limited access to clean water. In addition, increased relative humidity in homes where patient hold exchanges, a sharp temperature rise, heavy sweating and sand storms all contribute to bacterial contamination of the patient's environment, leading to peritonitis.

Gram-positive bacteria were the most frequent (60.78\%), including Staphylococcus aureus (45.12\%) and Pseudomonas aeruginosa (17.64\%). These bacteria are also the most commonly found in almost all the literature [2, 8-11]. This high incidence of gram-positive bacteria was due to the fact that these organisms live in saprophytic skin flora of humans. Low rates of antibiotic resistance in our study may be explained by the community origin of bacterial infections. No multi-resistant strains were isolated even among gramnegative bacteria. Vancomycin was active on isolated gram-positive microorganisms. This was also reassuring, as some antibiotics, especially imipenem and vancomycin, are not easily affordable in our country. The emergence of multi-resistant strains is a major danger to our patients. Zineb Lioussfi also reported the absence of strains resistant to vancomycin in his study [5].

The treatment applied as a first-line was bi-antibiotherapy including ceftriaxone injected intraperitoneally and ciprofloxacin orally on a daily basis for 5 days pending the results of susceptibility testing to tailor treatment.The ISPD (International Society of Peritoneal Dialysis) recommends treating staphylococcalinfections involving the PD fluid with a first-generation cephalosporin, such as cefazolin, which inhibits the last stage of peptidoglycan synthesis [6]. In the event of Gram-positive peritonitis, the ISPD recommends using a vancomycin and an effective glycopeptide against bacteria that works by binding to the peptidoglycan precursors involving assembly of dipeptide D-alanyl-D-alanine [12]. We did not use vancomycin in our study, as it was not available. As for Pseudomonas aeruginosa infections, the ISPD recommends combining two drugs with different modes of action, such as a $\beta$-lactam antibiotic and an aminoglycoside, and an oral quinolone may be applied as an alternative [6]. Noncompliance with ISPD recommendations on the treatment of infectious peritonitis was due to the lack of access to certain drug compounds in our hospital.

\section{Conclusion}

Peritoneal infections remain common in our patients and are mainly caused by Gram-positive bacilli. Prevention should rely on intensifying technical training and compliance with the rules of hygiene. Improved management of these peritoneal infections and acquisition of an effective technique requires awareness in the laboratory environment of the importance of good culture techniques and susceptibility studies extended to all anti-bacterial compounds. The increased availability of certain antibiotic compounds must be a priority for our hospitals.

\section{References}

1. Boudville N, Kemp A, Clayton P, Lim W, Badve SV, et al. (2012) Recent peritonitis associates with mortality among patients treated with peritoneal dialysis. J Am Soc Nephrol 23: 1398-1405.

2. Pérez Fontan M, Rodríguez-Carmona $A$, García-Naveiro $R$, Rosales $M$, Villaverde $\mathrm{P}$, et al. (2005) Peritonitis-related mortality in patients undergoing chronic peritoneal dialysis. Perit Dial Int 25: 274-284.

3. Piraino B, Bailie GR, Bernardini J, Gupta A, Holmes C, et al. (2005) Peritoneal dialysis-related infections recommendations: 2005 update. Perit Dial Int 25: 107-131.

4. Bonnet R, Cavallo JD, Chardon H, Courvalin P, Drugeon H, et al. (2010) Comité de l'antibiogramme de la société française de microbiologie Recommandations JO N¹9.

5. Zineb Lioussfi, Hakima R, Fatima E, Ouzeddoun N, Bayahia R, et al. (2012) Péritonites infectieuses en dialyse péritonéale continue ambulatoire au $\mathrm{CHU}$ de Rabat: profil bactériologique sur trois ans. Pan Afric Med 11: 4

6. Li PK, Szeto CC, Piraino B, de Arteaga J, Fan S, et al. (2016) ISPD Peritonitis Recommendations : 2016 Update on Prevention and Treatment. Perit Dial Int 36: 481-508.

7. Villarreal-Ríos E, Cárdenas-Maldonado C, Vargas-Daza ER, GaliciaRodríguez L, Martínez-González L, et al. (2014) Institutional and familial cost of patients in continuous ambulatory peritoneal dialysis. R.A.M.B 60: 335341.

8. Davenport A (2009) Peritonitis remains the major clinical complication of peritoneal dialysis: the London, UK, peritonitis audit 2002-2003. Perit Dial Int 29: 297-302.

9. deFijter CW, Oe LP, Nauta JJ, van der Meulen J, Verbrugh HA, et al. (1994) Clinical efficacy and morbidity associated with continuous cyclic compared with continuous ambulatory peritoneal dialysis. Ann Intern Med 120: 264-271.

10. Finkelstein ES, Jekel J, Troidle L, Gorban-Brennan N, Finkelstein FO, et al. (2002) Patterns of infection in patients maintained on long-term peritoneal dialysis therapy with multiple episodes of peritonitis. Am J Kidney Dis 39: 1278-1286.

11. Troidle L, Gorban-Brennan N, Kliger A, Finkelstein F (1998) Differing outcomes of gram-positive and gram-negative peritonitis. Am J Kidney Dis 32: 623-638.

12. Joshuan K, Charles R. Wira III (2014) Early identification and Management of patients with severe sepsis and shock in the emergency Departement. Em Med clinic 32: 759-776. 